\title{
COVID-19. EL CASO DE NICARAGUA. APORTES PARA ENFRENTAR LA PANDEMIA. HUETE-PÉREZ, JORGE. SERIE CIENCIA, TÉCNICA Y SOCIEDAD. ACADEMIA DE CIENCIAS DE NICARAGUA: MANAGUA, 2020
}

\author{
José María Gutiérrez Gutiérrez \\ Profesor emérito del Instituto Clodomiro Picado \\ Universidad de Costa Rica, Costa Rica
}

Recibido: 14/05/2020 - Aceptado: 15/05/2020

La publicación COVID-19, el caso de Nicaragua. Aportes para enfrentar la pandemia constituye un aporte importante de la Academia de Ciencias de Nicaragua en el contexto de la crisis sanitaria, social y económica generada por la pandemia COVID-19. El texto recoge ensayos de diversas personas con formación académica e inserción institucional variada, lo cual le da al trabajo una perspectiva interdisciplinaria e intersectorial que lo hace particularmente valioso. El texto trasciende el característico enfoque reduccionista biomédico con el que frecuentemente se estudian fenómenos de este tipo. Por el contrario, en esta obra se presentan perspectivas y análisis que van desde lo médico y salubrista hasta lo social y económico, pasando por el enfoque ecológico de este complejo fenómeno que ha impactado de una manera sin precedentes a la humanidad.

La comprensión de las pandemias como la que vivimos requiere de un abordaje transdisciplinario, el cual tome en cuenta la relación entre el modelo de desarrollo dominante, las profundas alteraciones ecológicas que ese modelo promueve, la inequidad e injusticia reinantes en la distribución de la riqueza y el bienestar y el debilitamiento generalizado de las instituciones públicas promovido por dicho modelo. Es en ese contexto que surge la pandemia de COVID-19. Por ende, la adecuada comprensión de los fenómenos asociados a esta tragedia sanitaria y la manera en que los países la enfrentan necesariamente deben incorporar esa visión holística e integradora. Esta perspectiva sistémica se ha denominado Ecosalud y constituye un campo emergente de gran impacto en el estudio de la realidad.

Además de presentar esta visión integradora, el libro constituye una clara denuncia, por parte de la mayoría de los autores, de la manera en que las autoridades del gobierno de Nicaragua han enfrentado y manejado esta epidemia. En particular, Jorge Huete-Pérez, editor general de la obra, lanza una crítica nítida y bien fundamentada a 
este manejo, tanto en la presentación del libro como en los capítulos finales de su autoría. Este posicionamiento crítico se complementa con varios "mensajes a la nación" elaborados por la Academia de Ciencias de Nicaragua, los cuales se presentan al final de la obra. La crítica a este abordaje, y a la negligencia que el mismo conlleva, atraviesa transversalmente el texto, ya que la mayoría de los autores inscribe su análisis en esta perspectiva crítica. Queda claro que la pandemia llega a Nicaragua en un contexto político e institucional caracterizado por la represión y el estrechamiento de espacios de disensión, proceso que se ha consolidado en los últimos dos años. No se puede comprender el manejo de esta crisis sanitaria si no es en ese contexto macro más amplio.

Las autoras y los autores, en mayor o menor medida, cuestionan abiertamente el manejo de la epidemia por parte del gobierno de Nicaragua. En uno de los artículos, escrito por cinco colegas del equipo de investigación del Centro de Biología Molecular de la Universidad Centroamericana (UCA), se dice:

Las autoridades de salud se han rehusado a implantar debidamente las recomendaciones de la OMS. No ha habido cierre de fronteras ni cuarentenas obligatorias, se promueven eventos masivos y niños y jóvenes continúan asistiendo obligatoriamente a clases. El país no cuenta tampoco con una estrategia efectiva y lo suficientemente sólida y congruente con la gravedad del problema que enfrentamos (84).

En los ensayos de carácter biomédico se repite con insistencia la relevancia de implementar cuanto antes medidas de contención de la propagación del virus, descentralizando e incrementando la puesta en marcha de pruebas diagnósticas para ubicar los casos y tener una idea clara de la magnitud de la expansión de la enfermedad. Los textos hacen énfasis en la necesidad de que los tomadores de decisiones en el ámbito político y salubrista se basen en criterios técnico-científicos y en la experiencia de otros países, aunado a las recomendaciones de la Organización Mundial de la Salud (OMS), y no en criterios basados en cálculos políticos.

Pasando a los aportes específicos de los diversos ensayos, Josefina Vigil y Melba Castillo Aramburu presentan sendos análisis sobre el impacto de esta epidemia en la educación pública en Nicaragua. Se menciona cómo la inequidad reinante en este país ha tenido un efecto dramático en el plano educativo en esta pandemia y cómo se ha marcado la diferencia entre los centros educativos públicos y privados. Con un 40 por ciento de la población en condiciones de pobreza, se hace muy difícil la reingeniería de los procesos educativos en la crisis sanitaria. El impacto de la brecha digital es enorme y resulta harto difícil para miles de familias la adaptación a la enseñanza digital. Se discute la necesidad de adaptarse creativamente a esta crisis en el plano educativo, mediante el uso de la radio y la televisión, así como el uso de los teléfonos celulares. También se analizan las posibilidades de apoyo escolar en los hogares y la necesidad de introducir reformas cualitativas en la filosofía didáctica. Como en el resto del 
mundo, la crisis ha puesto en evidencia la necesidad de revolucionar muchos aspectos de la educación.

Jessica Pérez-Reynosa desarrolla en su ensayo el tema de los desafíos socioeconómicos de la pandemia, en un país ya de por sí muy afectado en este ámbito. La implementación de las medidas sanitarias recomendadas por la OMS se complica en contextos socioeconómicos de pobreza y vulnerabilidad. Ello obliga a atener lo sanitario sin descuidar el impacto social y económico de la crisis. Cómo enfrentar una crisis económica de este calibre en un país que ya venía pasando por una recesión económica fuerte planea retos enormes para el gobierno y los sectores organizados de la sociedad. Al no darle la importancia que tiene esta epidemia, el gobierno ha dejado de prestar atención no solo al aspecto sanitario de la crisis, sino también a sus múltiples consecuencias sociales.

María Luisa Acosta analiza el tema de cómo el COVID-19 ha tenido un gran impacto en los pueblos indígenas y afrodescendientes. Luego de plantear que Nicaragua es un país multiétnico y pluricultural, la autora señala que en este, como en otros temas, la crisis sanitaria actual se monta sobre una crisis humanitaria que han venido sufriendo estos pueblos, producto del permanente despojo y agresión que sufren, como consecuencia de una política estatal de promoción de la colonización interna. En este contexto de inequidad, agresión y pobreza, es muy difícil para estas poblaciones implementar las medidas que se recomiendan para la contención de la epidemia. La necesidad del trabajo les impide el confinamiento y la vulnerabilidad de las personas adultas mayores pone en riesgo no solo su salud, sino también la transmisión de los saberes ancestrales. Por su parte, las diversas enfermedades que padecen los niños en dichas comunidades los hace más susceptibles a la posibilidad de cuadros graves por el coronavirus. Es esencial tomar en cuenta las particularidades culturales para enfrentar la crisis desde una visión intercultural, lo cual incluya el diálogo de saberes para generar respuestas adecuadas a sus contextos.

En un sentido similar se desarrolla el capítulo de Edwin Matamoros Chávez, quien se enfoca en el tema del incremento de las migraciones hacia la región Caribe. El autor analiza que uno de los posibles efectos de la poscrisis del COVID-19, a consecuencia del deterioro de las condiciones de vida y el incremento de la pobreza, es el incremento de las migraciones hacia las regiones indígenas y afrodescendientes en el Caribe nicaragüense. Esto se suma al proceso histórico de invasión, colonización y despojo que han sufrido estas regiones y estas poblaciones, proceso impulsado por el mismo Estado. Lo anterior obliga a generar condiciones que favorezcan la permanencia de sectores que podrían migrar a estas regiones, mediante proyectos de desarrollo socioeconómico en zonas empobrecidas del país. Se requiere proteger el derecho a la autonomía de los pueblos indígenas y hacer valer la legislación nacional e internacional vigente en este tema. En el contexto de las profundas inequidades existentes, el 
impacto de la pandemia en comunidades indígenas y afrodescendientes merece una atención especial.

Katherine Vammen y Salvador Montenegro discuten el tema del agua en Nicaragua con relación a la crisis del COVID-19. La autora y el autor plantean la estrecha relación entre la degradación estructural de los recursos hídricos en dicho país, la cual se ha acentuado en los últimos años, y la crisis sanitaria actual. El contar con suministro de agua potable es un elemento fundamental en esta crisis, dada la relevancia de la higiene personal y la hidratación en la prevención de la enfermedad. El ensayo discute las sequías y los procesos de desertificación producto de la deforestación descontrolada, el incremento de la ganadería extensiva y, en general, el mal manejo del ambiente. Se plantea la necesidad de establecer programas de gestión y protección del recurso hídrico a nivel local y de establecer programas de manejo integral y de planificación hídrica, enmarcados en un sistema nacional de información, todas tareas pendientes de gran urgencia en el país. Se insiste en la relevancia de generar conocimiento sobre este tema y de aplicarlo en dicha gestión de este recurso. El ensayo también enfoca un tema sobre el que se está investigando en diversos países, cual es el de la presencia y permanencia del SARS Cov-2 en aguas residuales. Aún no se cuenta con respuestas claras al respecto, pero este aspecto tiene fuertes implicaciones en el manejo de las aguas residuales.

El tema del impacto del COVID-19 sobre el medioambiente es desarrollado por Jean-Michel Charles Maer. Un fenómeno de tan alto impacto como esta epidemia tiene implicaciones en muchos aspectos de la vida de un país, incluyendo por supuesto el ambiental. Se plantea cómo el contacto y consumo cada vez mayores de animales silvestres, como parte de las enormes alteraciones generadas por el ser humano en la naturaleza, constituyen escenarios donde el paso de virus y otros microorganismos de estos animales a las personas se hace cada vez más factible, como ha ocurrido con esta pandemia y con epidemias previas. Problemas ambientales como el manejo de desechos urbanos, incluyendo los hospitalarios, cobran particular relevancia en una epidemia.

La crisis sanitaria, que ha derivado en una profunda crisis socioeconómica, hace que las personas en condiciones de alta vulnerabilidad migren a nuevos territorios, lo cual incluye áreas protegidas y otras ocupadas por comunidades indígenas y afrodescendientes. El sistema de áreas protegidas, ya de por sí muy debilitado por muchas razones, se afecta aún más en esta crisis. El autor propone una serie de medidas para afrontar una situación tan grave, dentro de las cuales se encuentran medidas salubristas que han sido deficientes en Nicaragua, por ejemplo, la reparación económica de las personas más afectadas por la crisis, el control de las migraciones a áreas protegidas, la producción de alimentos para el mercado interno y el mejoramiento de la educación. Se trata de un abordaje integral dentro del paradigma de la Ecosalud, es decir, abordar los temas de salud en el contexto de las alteraciones en los ecosistemas. 
Oswalt Jiménez presenta un ensayo sobre un tema fundamental en esta crisis: la seguridad alimentaria. En el contexto de la globalización neoliberal, el tema de la seguridad alimentaria ha pasado a un segundo plano. La actual crisis del COVID-19 ha vuelto a poner sobre el tapete la relevancia de la seguridad o soberanía alimentaria. El autor elabora un análisis sobre cómo la crisis afecta la producción local de alimentos y cómo debilita a los sectores y familias que basan su ingreso en el mercado local de estos productos. Por ejemplo, la medida introducida por el gobierno de El Salvador para fomentar la importación de productos básicos desde Nicaragua ha tenido un efecto negativo en cuanto a desabastecimiento en este país. La reducción de la demanda por alimentos, debido a la crisis económica, genera un círculo vicioso que hace bajar sus precios. Los trabajadores y las trabajadoras agrícolas, al continuar con su labor por razones de supervivencia material, corren el riesgo de infectarse por no poder mantener medidas de cuarentena y distanciamiento social. El transporte de alimentos también se ve afectado. Todo ello obliga al Estado y a la sociedad civil a implementar medidas para proteger al productor local de alimentos, favoreciendo así el autoconsumo. Se requiere estimular la producción de alimentos a escala local. Además, son necesarias medidas como la asistencia técnica a productores, el aseguramiento de mercados, la prevención del desperdicio de alimentos, el uso de medios digitales para la comercialización (lo cual es afectado por el tema de la brecha digital) y el desarrollo de políticas fiscales progresivas.

Dionisio Rodríguez trabaja el concepto de la crisis del COVID-19 como un desastre y refiere que la Organización de las Naciones Unidas (ONU) ha creado un marco global para la gestión de desastres de diverso tipo, cuya implementación sería de gran beneficio en este caso. El concepto de "riesgo" de desastre involucra tres elementos: amenaza, exposición y vulnerabilidad. En el caso de Nicaragua, la vulnerabilidad se potencializa por la pobreza, la falta de políticas de prevención de riesgo y los frágiles sistemas sanitario, socioeconómico y político. En este contexto, la epidemia del COVID-19 constituye un riesgo enorme de desastre. A ello se suma el hecho de que las autoridades no han acogido las recomendaciones de la OMS sobre cómo manejar la pandemia. Es necesario atender el tema mediante un plan de comunicación y sensibilización públicas, el cual no ha sido implementado por el gobierno, aunque sí se hacen esfuerzos por parte de sectores de la sociedad civil.

El texto que comentamos incluye dos capítulos sobre aspectos estrictamente biomédicos y epidemiológicos del tema del COVID-19. En uno de ellos, cinco autores y autoras del Centro de Biología Molecular de la UCA resumen los aspectos virológicos, epidemiológicos y clínicos del problema. Se explica cómo la alta transmisibilidad de este coronavirus y los canales de comunicación global han posibilitado el desarrollo de la pandemia, con lo cual se genera un problema sanitario que ha saturado los sistemas de salud y generado un impacto socioeconómico devastador. Se discuten también las opciones terapéuticas existentes. Se comenta que para aplicar las recomendaciones 
para aplanar la curva de nuevos casos se requieren medidas como el diagnóstico temprano, el rastreo epidemiológico y el monitoreo de contactos, además del distanciamiento social y el frecuente lavado de manos. El ensayo señala cómo es evidente que en Nicaragua se da un enorme subregistro de la magnitud de la epidemia por parte de las autoridades y como estas se han negado repetidamente a adoptar las recomendaciones emanadas de la OMS. Al final, llaman a recapacitar y a corregir el rumbo, para evitar una crisis humanitaria de proporciones enormes.

Otro capítulo con énfasis biomédico, preparado por Erwin Aguilar Gámez, se enfoca en un aspecto muy particular de los efectos del coronavirus: las alteraciones en los riñones. En los casos graves de esta enfermedad, el organismo reacciona ante el virus generando una respuesta inflamatoria sistémica que se ha denominado "tormenta de citoquinas". Ello afecta con particular severidad los riñones, lo cual se describe como una lesión renal aguda en pacientes severos.

El editor de esta obra, Jorge Huete-Pérez, presenta un ensayo sobre la necesidad urgente de un diagnóstico masivo de COVID-19 en Nicaragua, para conocer la verdadera magnitud del problema y para implementar acciones salubristas efectivas basadas en evidencias. El autor comenta que Nicaragua cuenta con capacidades técnicas en diversas instituciones para realizar estas pruebas en gran escala, pero a la vez señala que el gobierno no ha favorecido esta línea de acción. Se mencionan las posibilidades que dan las pruebas serológicas, las cuales detectan anticuerpos contra el coronavirus en la sangre de personas que han sufrido la infección. Alienta a conocer que organizaciones nicaragüenses, como la Academia de Ciencias, el Comité Científico Multidisciplinario y la Unidad Médica Nicaragüense, así como sectores académicos universitarios y de otros ámbitos de la sociedad civil, han tomado iniciativas para informar a la población y para promover medidas sanitarias en la dirección correcta. El mismo autor presenta otro ensayo sobre el peligro inminente de la transmisión comunitaria del SARS Cov-2 en Nicaragua, de lo cual hay evidencias fehacientes. Lamentablemente, no se cuenta con datos fidedignos que señalen la verdadera magnitud de este fenómeno. Huete-Pérez insiste en la urgente necesidad de introducir el diagnóstico en gran escala e insta al Ministerio de Salud (MINSA) a descentralizar el diagnóstico del COVID-19, efectuar las pruebas a todas las personas que muestren un cuadro respiratorio agudo y a incorporar en estos esfuerzos a los laboratorios de biología molecular de los centros universitarios que manejan esa tecnología.

La obra que reseñamos tiene el enorme mérito de unir a especialistas de diversos ámbitos y enfoques en un valioso esfuerzo interdisciplinario para presentar diferentes ángulos del problema del COVID-19 en Nicaragua. Resulta estimulante el abordaje multifacético, que deja ver la complejidad de las implicaciones de una crisis de este calibre. Pese a que la calidad de los ensayos es un tanto desigual, todos aportan en la comprensión de ángulos diversos del tema. Debe tenerse en cuenta que la evolu- 
ción de esta pandemia y de su comprensión varían día a día, conforme más información aparece y el impacto de la crisis es más evidente en diversos planos. En este sentido, es probable que algunos de los conceptos emitidos en esta obra pierdan vigencia con el surgimiento de nuevos datos; pero sin duda permanecerá el valor de este abordaje de carácter integral. El texto no solo analiza varios aspectos del COVID-19, sino que presenta una fuerte visión crítica de la forma en que las autoridades nicaragüenses han afrontado, o dejado de afrontar, la crisis. Se presentan posiciones valientes que denuncian la negligencia existente, a la vez que muestran esfuerzos en la sociedad civil para enfrentar el problema. Queda claro de la lectura del libro que existe una profunda vinculación entre el entorno político represivo y autoritario reinante en Nicaragua y el impacto de la crisis sanitaria, así como la enorme tragedia humana que causa una epidemia así en los sectores más vulnerables de la población. Esta es una obra que vale la pena leer con detenimiento.

José María Gutiérrez Gutiérrez. Profesor emérito del Instituto Clodomiro Picado, perteneciente a la Facultad de Microbiología de la Universidad de Costa Rica. Ha trabajado durante 45 años en dicho instituto en proyectos de investigación relacionados con serpientes, venenos y antivenenos. Ha sido docente de la Facultad de Microbiología, donde ha impartido cursos de grado y posgrado en Inmunología, Métodos de Investigación, Bioquímica y Patología Celular. Fue director, subdirector y coordinador de la División Académica del Instituto Clodomiro Picado y director del Programa de Posgrado en Microbiología, Parasitología y Química Clínica, así como coordinador del Programa de Posgrado en Ciencias Biomédicas Centroamérica Instituto Karolinska. Fungió como asesor de la Organización Mundial de la Salud en materia de antivenenos. También ha coordinado las actividades de cooperación internacional del Instituto Clodomiro Picado. Es editor de las revistas Toxicon y PLoS Neglected Tropical Diseases.

Contacto: jose.gutierrez@ucr.ac.cr

ORCID: https://orcid.org/0000-0001-7038-8301 